\title{
Snoring detection during auto-nasal continuous positive airway pressure
}

\author{
F. Lofaso*,\#, K. Leroux", M.A. Quera-Salva*, G. Mroue*, M.P. D'Ortho*, D. Isabey", \\ B. Louis ${ }^{\#}$
}

Snoring detection during auto-nasal continuous positive airway pressure. F. Lofaso, $K$. Leroux, M.A. Quera-Salva, G. Mroue, M.P.D'Ortho, D. Isabey, B. Louis. (C)ERS Journals Ltd 2002.

ABSTRACT: A bench study using an artificial lung model was performed to evaluate the snoring detection sensitivity of six (commercially available) auto-nasal continuous positive airway pressure (NCPAP) devices.

Snoring was simulated by a loudspeaker connected to the lung model and abruptly activated during $1 \mathrm{~s}$ of each inspiratory period to induce pressure oscillation. The oscillation frequencies chosen were $30,60,90$, and $120 \mathrm{~Hz}$. For each frequency, the amplitude of the pressure oscillation produced by the loudspeaker was adjusted to find the threshold at which the auto-nCPAP devices detected snoring.

Differences in pressure-amplitude thresholds of up to three-fold were found across auto-nCPAP devices. A randomized clinical study to compare the effects of the least sensitive (Virtuoso LX; Respironics, Nantes, France) and one of the most sensitive, (Goodknight 418A; Malinckrodt, Nancy, France) devices, in two groups of six patients with obstructive sleep apnoea syndrome was then conducted. Goodknight $418 \mathrm{~A}$ was more sensitive than Virtuoso LX for detecting snoring (mean \pm SD $92 \pm 11 \%$ versus $50 \pm 39 \%$ respectively, $\mathrm{p}=\mathbf{0 . 0 3}$ ).

To conclude, striking differences exist between auto-nasal continuous positive airway pressure devices in sensitivity for detecting snoring.

Eur Respir J 2002; 19: 108-112.

\begin{abstract}
*Service de Physiologie, Explorations Fonctionnelles et Centre d'Investigations Technologiques, Hôpital Raymond Poincaré Garches, ${ }^{\text {\#} I n s t i t u t ~}$ National de la Santé et de la Recherche Médicale, Hôpital Henri Mondor, Créteil, France and Association d'Entraide des Polios et Handicapés, Puteaux, France.
\end{abstract}

Correspondence: F. Lofaso, Service de Physiologie-Explorations Fonctionnelles, Hôpital Raymond Poincaré, 92380 Garches, France.

Fax: 33147107943

Keywords: Continuous positive airway pressure, obstructive sleep apnoea

Received: February 82001

Accepted after revision September 14 2001

This study was supported by the Institut national de la Santé et de la Recherche Médicale.
Nasal continuous positive airway pressure (nCPAP) was introduced in 1981 by Sullivan et al. [1] and has improved the treatment and prognosis of patients with obstructive sleep apnoea syndrome considerably. In practice, the optimal nCPAP level is a "trade-off" between pressure-related side-effects and efficacy in preventing upper airway obstruction during sleep [2]. This optimal level is generally determined during a total or split-night study. Follow-up is needed to verify that the selected level remains appropriate for the patient's needs, since the minimal effective pressure can vary over time depending on weight variations, sleep deprivation, nasal obstruction, and alcohol or hypnotic agent ingestion [3]. In addition, this minimal pressure can change during a given night, according to body position and/or sleep stage [3].

To try to improve the efficacy in relieving upper airway obstruction and the acceptability of nCPAP, new nCPAP devices have been developed that use noninvasive indirect assessment of upper airway obstruction to continuously adjust the pressure around the minimal level that prevents abnormal breathing and arousal. These devices use noninvasive indirect methods to detect respiratory events such as obstructive apnoeas, hypopnoea, snoring and flow limitation [4]. Detection of flow limitation and differentiation between central and obstructive apnoeas are available only with the most sophisticated devices (AutoSet; ResCare, Sydney, Australia and Goodknight 418P, Malinckrodt, Nancy, France). Because auto-nCPAP devices cannot reliably differentiate central hypopnoeas from obstructive hypopnoeas, the latter being easily detected as flow limitation, hypopnoea detection is not used at all by some autonCPAP devices (Autoset) to adjust pressure and is used optionally by other devices (Goodknight 418P). In contrast, nearly all auto-nCPAP devices detect snoring. No studies have evaluated the snoring detection performance of these devices. The authors compared snoring detection by several auto-nCPAP devices.

A bench study was first conducted to examine the performance of six commercially available autonCPAP devices (table 1). The second part of the study evaluated the clinical relevance of differences found between two auto-nCPAP devices during the first part of the study. 
Table 1. - Auto-nasal continuous positive airway pressure devices tested

\begin{tabular}{lcc}
\hline Brand & Model & Type of detection \\
\hline Devilbiss (Parcay Meslay, France) & Horizon Auto Adjust & S, FL, H, A \\
Mallinckrodt (Les Ulis, France) & Goodknight 418A & S, H\#, A \\
Mallinckrodt (Les Ulis, France) & Goodknight 418P & S, FL, H HA $^{\#}$ OA \\
Res Med (Saint Priest, France) & Autoset T & S, FL, OA \\
Respironics (Nantes, France) & Virtuoso LX & S, A \\
Taema (Antony, France) & Eclipse Auto & S, FL, A \\
\hline
\end{tabular}

S: snoring; FL: flow limitation; H: hypopnoea; A: apnoea; OA: obstructive apnoea. \#: optional.

\section{Methods}

\section{Experimental bench study}

As presented in Figure 1a, each auto-nCPAP device was connected to a standard circuit comprising a hose with a 4-mm lateral expiratory hole located a few centimetres from its tip. Pressure and flow were measured at the end of the hose using a differential transducer (model 8510 B2; Endevco Le Pré-Saint Gervals, France) and a pneumotachograph (Fleisch no. 2, Lausanne, Switzerland) connected to a differential transducer (Validyne DP $45, \pm 3 \mathrm{cmH}_{2} \mathrm{O}$, Northridge, CA, USA). Tidal volume $(V \mathrm{~T})$ was obtained by integrating the flow signal. Signals were digitized at
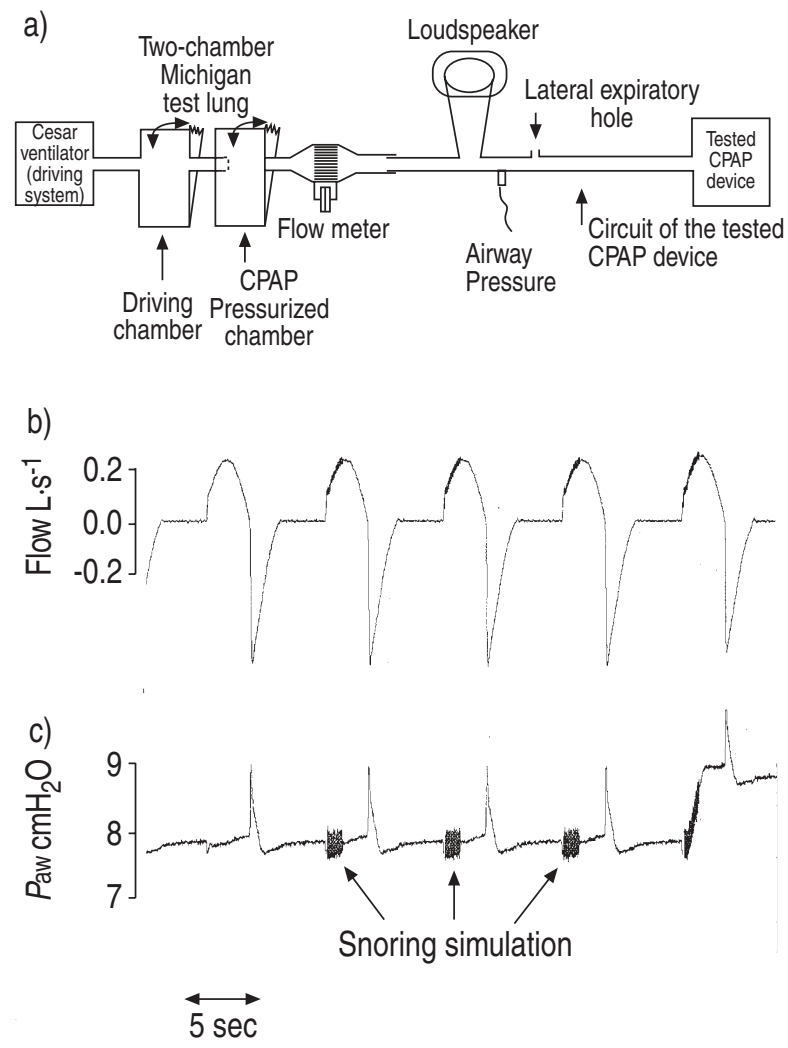

Fig. 1.-a) Experimental set-up. b) Illustration of flow recording and c) mean pressure $(P$ aw $)$ at the moment when snoring was simulated. The auto-nasal continuous positive airway pressure device increased its pressure level after three-cycles of simulated snoring. CPAP: continuous positive airway pressure.
$1000 \mathrm{~Hz}$ and sampled by an analogic/numeric system (MP100, Biopac Systems, Goleta, CA, USA).

To simulate repeated inspiratory efforts, the experimental set-up was connected to a two-chamber Michigan test lung (fig. 1a). One chamber was connected to, and powered by, a Cesar ventilator (Taema, Antony, France) (driving chamber), whereas the other chamber (CPAP pressurized chamber) was connected to the auto-CPAP ventilator under test. The Cesar ventilator was set to ensure a respiratory frequency of 8 cycles $\cdot \mathrm{min}^{-1}$, an inspiratory time of 2.8 and a $V \mathrm{~T}$ of $660 \mathrm{~mL}$ with a curved inspiratory flow contour that was gradually increased and decreased.

The auto-nCPAP devices were tested after pressure adjustment to 4,8 and $12 \mathrm{cmH}_{2} \mathrm{O}$. To simulate snoring, a loudspeaker connected to the circuit between the auto-nCPAP and the CPAP pressurized chamber (fig. 1a) was activated abruptly to produce a pressure oscillation during $1 \mathrm{~s}$ of each inspiratory period (fig. 1b). The frequencies chosen were 30, 60, 90, and $120 \mathrm{~Hz}$. For each frequency, the amplitude of the pressure oscillation produced by the loudspeaker was adjusted to identify the smallest value at which the auto-CPAP detected snoring. This threshold was validated by checking that no snoring was detected when an amplitude of $\leqslant 0.02 \mathrm{cmH}_{2} \mathrm{O}$ below the threshold was maintained for $5 \mathrm{~min}$. The effect of increasing and decreasing the duration of pressure oscillation from the total inspiratory time to $0 \mathrm{~s}$ or of substituting an expiratory pressure oscillation for the inspiratory pressure oscillation, on the snoring detection threshold was also evaluated.

\section{Clinical study}

Apparatus tested. Two auto-nCPAP devices were tested, the device that was least sensitive (Virtuoso LX; Respironics, Nantes, France) and one of the devices that were most sensitive (Goodknight 418A) in detecting snoring in the bench study. The Goodknight 418A was chosen because as with the Virtuoso LX, it detects snoring and apnoeas only.

Patients and clinical trial. This study was approved by the Research Ethics Committee of the authors' institution. All patients gave written informed consent to participate in the study. Twelve male patients with sleep apnoea syndrome requiring nCPAP were randomly allocated to two groups of six. Both groups received auto-nCPAP treatment during polysomnography. Auto-nCPAP was delivered by the 
Virtuoso LX in one group and by the Goodknight 418A in the other. Polysomnography included electroencephalography (EEG), electro-oculography (EOG), chin electromyography (EMG), nasal flow measured by a Fleisch No. 2 pneumotachograph connected to a differential pressure transducer (Validyne MP45 \pm $5 \mathrm{cmH}_{2} \mathrm{O}$ ), thoracic and abdominal movements, arterial pulse oximetry (Nellcor BS, Nellcor Inc., Hayward, CA, USA), nasal mask pressure measured by a differential pressure transducer (Validyne MP45 \pm $35 \mathrm{cmH}_{2} \mathrm{O}$ ), and oesophageal pressure (Gaeltec, Dunvegan, Isle of Skye, UK).

The initial nCPAP level was always set at the smallest possible value, i.e. $4 \mathrm{cmH}_{2} \mathrm{O}$. The algorithm provided by each manufacturer allowed the nCPAP level to increase according to whether snoring and/or apnoeas were detected.

Data analysis. On each polysomnography recording, the number of snoring events during objectively measured sleep was counted by one of the authors, who did not know which auto-nCPAP device had been used. A snoring event was defined as detection of pressure and flow oscillations $[5,6]$ during three consecutive respiratory cycles with an increase in the oesophageal pressure swing. The percentage of snoring events followed by a pressure increase was calculated for each patient. The percentage of pressure increases without concomitant snoring or apnoea events ("inappropriate pressure increases") was also calculated.

Statistics. Data are presented as means \pm SD. Comparisons were made using unpaired t-tests. The level of significance was set at $5 \%$.

\section{Results}

\section{Experimental bench study}

For each pressure-oscillation frequency produced by the loudspeaker and for each CPAP level, the pressure-oscillatlion amplitude threshold for snoring detection by each device tested is shown in figure 2 . Threshold differences of up to three-fold were found between auto-nCPAP devices. As determined by the algorithms, the increase in nCPAP pressure was observed after three-cycles of simulated snoring with the Goodknight 418P and 418A and the Virtuoso LX, six-cycles with the Autoset $\mathrm{T}$, ten-cycles with the Horizon auto-adjust, and 1-2 min with the Eclipse auto. The nCPAP level increase was $\sim 0.2 \mathrm{cmH}_{2} \mathrm{O}$ with the Autoset $\mathrm{T}$ and the Horizon auto-adjust, $1 \mathrm{cmH}_{2} \mathrm{O}$ with the Goodknight 418P, Goodknight 418A, and Eclipse auto; and $2 \mathrm{cmH}_{2} \mathrm{O}$ with the Virtuosa LX.

No effect of duration of pressure oscillation on snoring detection thresholds was observed, except that each device detected snoring only after a minimal pressure-oscillation duration, probably determined by each manufacturer's algorithm. This minimal duration was $\sim 0.5 \mathrm{~s}$ for the Goodknight $418 \mathrm{~A}$, the Goodknight $418 \mathrm{P}$ and the Autoset $\mathrm{T}$ and about $0.3 \mathrm{~s}$ for the Virtuoso LX and Horizon. Snoring detection with the Eclipse auto required at least 30 oscillations and therefore, the minimal duration of pressure oscillation varied with the oscillation frequency, from $<0.3 \mathrm{~s}$ at $120 \mathrm{~Hz}$ to $1 \mathrm{~s}$ at $30 \mathrm{~Hz}$. In addition, Autoset $\mathrm{T}$ and Horizon auto adjust were apparently not able to detect snoring when pressure oscillation occurred during expiration.

\section{Clinical study}

The main characteristics of the two patient groups and the performance of the two auto-nCPAP devices are reported in table 2 . The two patient groups were similar, whereas snoring detection sensitivity was significantly lower with the Virtuoso LX than with the Goodknight 418A. No unexplained increases in airway pressure were observed.

\section{Discussion}

The present bench study is the first to demonstrate differences in pressure-oscillation detection between auto-nCPAP devices.

The oscillation frequencies chosen to simulate snoring were within the range of those previously observed during snoring in humans: LIISTRO and co-workers $[5,6]$ demonstrated that snoring was associated with high-frequency oscillation $(40-90 \mathrm{~Hz}$ during snoring through the nose and around $30 \mathrm{~Hz}$ during snoring through the mouth) of the soft palate, pharyngeal walls, epiglottis, and tongue, resulting in airway pressure and flow vibrations.

For all devices, it was observed that the sensitivity of snoring detection decreased when the nCPAP level increased. This finding is probably ascribable to the increase in turbine noise associated with increasing turbine speed. It suggests that snoring sensitivity may be lower in those patients who respond best to high nCPAP levels.

The clinical relevance of the differences observed in the bench study were also demonstrated; one of the most sensitive devices in the bench study was more sensitive for detecting snoring in patients than the least sensitive device in the bench study. In addition, the clinical study established that the most sensitive device remained as specific as the least sensitive device. The authors recently conducted a clinical study of an auto-nCPAP device (rapid eye movement (REM)+auto) that was the precursor of the Goodknight 418A and had similar sensitivity for snoring detection (unpublished data). It was found that this device induced no detrimental pressure increases [7, 8]. Moreover, in one of the 15 patients, who was described by their bed partner as an almost continuous snorer, this auto-nCPAP device failed to detect snoring because the sound was not loud enough [7]. This result was confirmed by a study reported in abstract form [9], in which snoring was recorded by a stethoscope secured to the trachea in 13 patients who used the precursor of the Goodknight 418A. The investigators reviewed the polysomnographical traces while listening with earphones to the stethoscope recording in order to identify snoring. The 

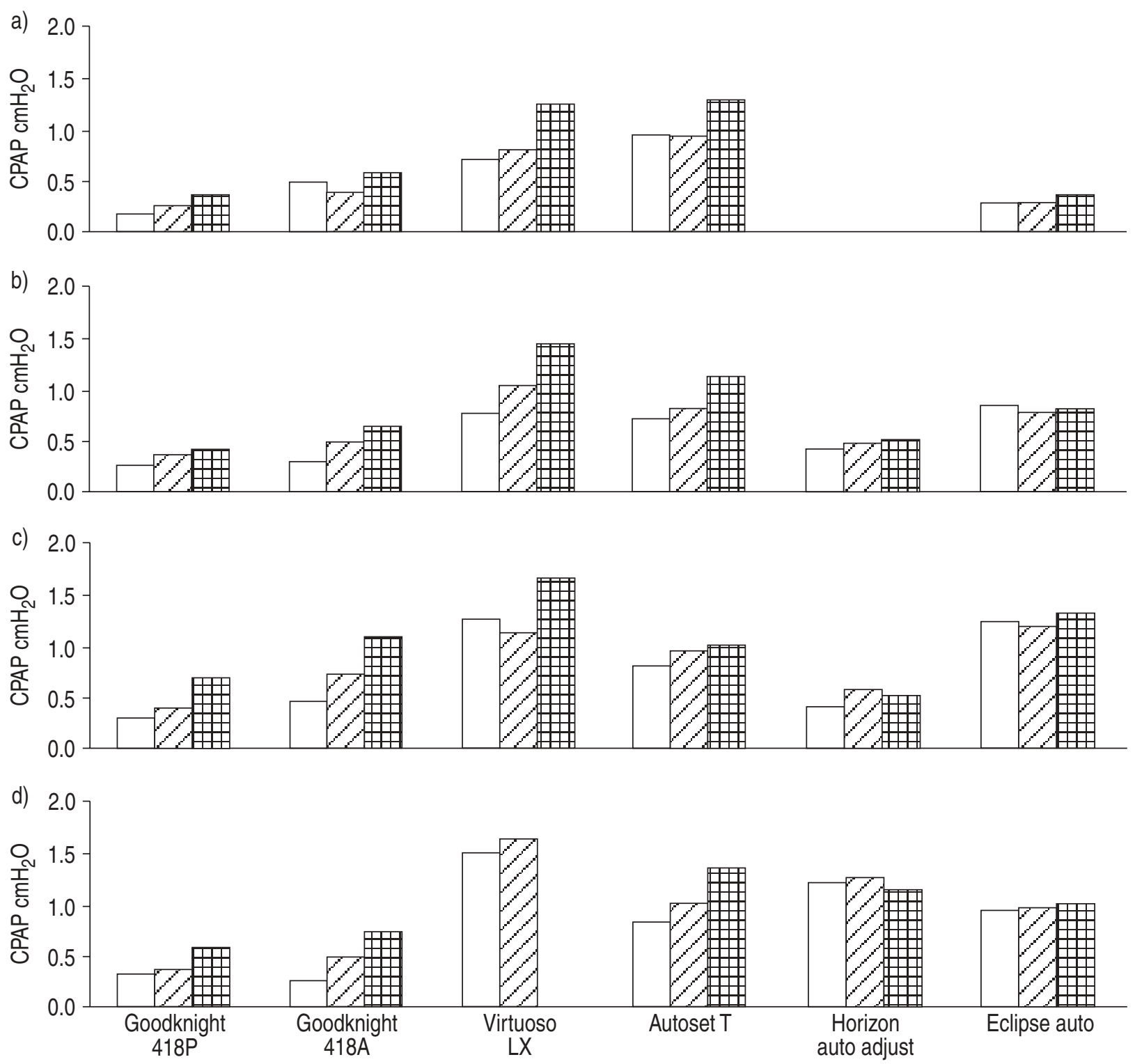

Fig. 2.-Comparison of the pressure oscillation amplitude threshold produced by the loudspeaker and detected as snoring for each continuous positive airway pressure (CPAP) level ( $\square: 4 \llbracket: 8$, and 囲 $12 \mathrm{cmH}_{2} \mathrm{O}$ ), oscillation frequency a) 30 , b) 60 , c) 90 , and d) $120 \mathrm{~Hz}$ ) and auto-nCPAP device. Because the amplitude thresholds of Horizon auto adjust at $30 \mathrm{~Hz}$ and of Virtuoso LX at $120 \mathrm{~Hz}$ and 12 $\mathrm{cmH}_{2} \mathrm{O}$ were $>2 \mathrm{cmH}_{2} \mathrm{O}$ they are not shown in the figure.

Table 2. - Characteristics of the patients and performance of the two auto-nasal continuous positive airway pressure devices tested

\begin{tabular}{lccc}
\hline & $\begin{array}{c}\text { Virtuoso } \\
\text { LX } \\
\text { group }\end{array}$ & $\begin{array}{c}\text { Goodknight } \\
\text { 418P group }\end{array}$ & $\begin{array}{c}\text { Statistical } \\
\text { analysis }\end{array}$ \\
\hline Patients n & 6 & 6 & \\
Age yr & $56 \pm 8$ & $49 \pm 10$ & $\mathrm{NS}$ \\
Body mass index $\mathrm{kg} \cdot \mathrm{m}^{-2}$ & $28 \pm 5$ & $28 \pm 6$ & $\mathrm{NS}$ \\
AHI·h of sleep & & & \\
Snoring detection & $46 \pm 10$ & $50 \pm 30$ & $\mathrm{NS}$ \\
$\quad$ sensitivity \% & $50 \pm 39$ & $92 \pm 11$ & $\mathrm{p}=0.03$ \\
$\begin{array}{l}\text { Inappropriate pressure } \\
\text { increases \% }\end{array}$ & 0 & 0 & \\
\hline
\end{tabular}

Values are presented mean \pm SD. AHI: apnoea/hypopnoea index during diagnostic polysomnography. device increased its pressure in response to only $84 \pm 6 \%$ of snoring events [9]. Similarly, using a less sensitive (more demanding) standard of reference for diagnosing snoring, it was observed that the Goodknight 418A increased its pressure response to $92 \pm 11 \%$ of snoring events. This suggests that one of the most sensitive devices may fail to respond consistently to low-intensity snoring and that similar failure may be even more common with less sensitive devices.

To conclude, important differences in snoring detection exist between commercially available autonasal continuous positive airway pressure devices, under both bench study and clinical conditions. The more sensitive devices seem acceptable, whereas the less sensitive fail to ensure effective prevention of snoring. In addition, the major differences between 
auto-nasal continuous positive airway pressure devices suggests that further studies are needed to evaluate and compare such devices, particularly the new devices that use detection of flow limitation or those that continuously measure the impedance and/or resistance of the respiratory system using noninvasive means such as the forced oscillation method [10, 11].

\section{References}

1. Sullivan C, Issa F, Berthon-Jones M, Eves L. Reversal of obstructive sleep apnoea by continuous positive airway pressure applied through the nares. Lancet 1981; i: 862-861.

2. Directors of ATS board. Indications and standards for use of nasal continuous positive airway pressure (CPAP) in sleep apneas syndromes. Am J Respir Crit Care Med 1994; 150: 1738-1745.

3. Polo O, Berthon-Jones M, Douglas N, Sullivan C. Management of obstructive sleep apnoea/hypopnoea syndrome. Lancet 1994; 344: 656-660.

4. Berthon-Jones M. Feasibility of a self-setting CPAP machine. Sleep 1993; 16: S120-S123.

5. Liistro G, Stänescu D, Veriter C, Rodenstein D, Aubert-Tulkens G. Pattern of snoring in obstructive sleep apnea patients and heavy snorers. Sleep 1991; 14 : 517-525.

6. Liistro G, Stânescu D, Veriter C. Pattern of simulated snoring is different through mouth and nose. $J$ Appl Physiol 1991; 70: 2736-2741.

7. Lofaso F, Lorino A-M, Duizabo D, et al. Evaluation of an auto-CPAP device based on snoring detection. Eur Respir J 1996; 9: 1795-1800.

8. Berkani M, Lofaso F, Chouaid C, et al. CPAP titration by an auto-CPAP device based on snoring detection: a clinical trial and economic considerations. Eur Respir J 1998; 12: 759-763.

9. Viau F, Darne C, Jachym-Frechet M, Haniez F, Mermillon V, Le Tinier J. Evaluation of a continuously adjusted CPAP driven by snoring (AutoCPAP SEFAM). In: From Snoring to Sleep Apnea Syndrome: Therapeutic Approach. Lyon's World Congress, Lyon, 1995.

10. Lorino A, Lofaso F, Duizabo D, et al. Respiratory resistive impedance as an index of airway obstruction during NCPAP titration. Am J Respir Crit Care Med 1998; 158: 1465-1470.

11. Randerath W, Schraeder O, Galetke W, Feldmeyer F, Rühle K. Autoadjusting CPAP therapy based on impedance efficacy, compliance and acceptance. Am J Respir Crit Care Med 2001; 163: 652-657. 